\title{
Parametrical analysis of the railways dynamic response at high speed moving loads
}

\author{
Michele Agostinacchio • Donato Ciampa • \\ Maurizio Diomedi $\cdot$ Saverio Olita
}

Received: 26 June 2013/Revised: 22 August 2013/Accepted: 24 August 2013/Published online: 17 September 2013

(C) The Author(s) 2013. This article is published with open access at Springerlink.com

\begin{abstract}
The paper introduces some findings about a sensitivity analysis conducted on every geometrical and mechanical parameters which characterize the use of a railway superstructure at the high velocity. This analysis was carried out by implementing a forecast model that is derived from the simplified Gazetas and Dobry one. This model turns out to be particularly appropriate in the explication of problems connected to high velocity, since it evaluates both inertial and viscous effects activated by the moving load speed. The model implementation requires the transfer function determination that represents the action occurred by the bed surfaces on the railway and it therefore contains information concerning the geometrical and the mechanical characteristics of the embankment, of the ballast and of the sub-ballast. The transfer function $\mathrm{H}$ has been evaluated with the finite elements method and particularly, by resorting the ANSYS ${ }^{\circledR}$ code with a harmonic structural analysis in the frequencies field. The authors, from the critic examination of the system's dynamics response in its entirety, glean a series of observations both of a general and a specific character, finally attaining a propose of a design modification of the standard railway superstructure at the high velocity of train operation adopted today especially in Italy.
\end{abstract}

\footnotetext{
M. Agostinacchio - D. Ciampa · M. Diomedi · S. Olita $(\square)$

School of Engineering, University of Basilicata, Viale

dell'Ateneo Lucano 10, 85100 Potenza, PZ, Italy

e-mail: saverio.olita@unibas.it

M. Agostinacchio

e-mail: michele.agostinacchio@unibas.it

D. Ciampa

e-mail: donato.ciampa@unibas.it

M. Diomedi

e-mail: maurizio.diomedi@unibas.it
}

Keywords Railways - Dynamic response - High velocity · Sensitivity analysis

\section{Introduction}

The improvement of the design quality and the decrease of the maintenance costs, with a particular estimation of the safety levels of a railway network, occur after a proper evaluation of the influence practiced on the railways dynamic response by the superstructure geometrical and mechanical parameters.

This estimation can be made through an improvement process of these given parameters, after a careful sensitivity analysis, to focus the conducted role in the railways superstructure operation at the high velocity.

In order to better focus on the research context of this work, it is useful to quote a short scientific overview about this subject.

The dynamic response of the Eulero-Bernoulli beam, strained by a moving load, has been a subject of numerous studies in the civil engineering.

Kenney [1] has studied the effect of the viscous damping, starting from the analytic solution of the response of the infinitively extended Eulero-Bernoulli beam resting on Winkler foundation.

Fryba [2], instead, has analyzed the response of an unbounded elastic body subjected to a dynamic load by applying a triple Fourier transform. The solution has been obtained by resorting the concept of equivalent stiffness of the support structures, evaluating every compatible velocity and damping values.

Gazetas and Dobry [3] have developed a simplified model to study the variation of the foundation damping coefficient under the hypothesis of a planar deformation 
and axial symmetric load conditions. In spite of the simplified hypothesis adopted, the solution obtained in a closed form turns out to be convergent with that given by the rigorous methods available in literature, valuable for the linear, irregular, and deep foundations leaned or inserted in an homogeneous material and subjected to horizontal and vertical vibrations.

Sun [4] has proposed a solution in a closed form for the response of a beam resting on a Winkler ground under a linear dynamic load applying the two-dimensional Fourier transform and the Green function.

Mallik et al. [5] have investigated on the steady-state response of the Eulero-Bernoulli beam resting on an elastic ground under a concentrated load moving at fixed velocity.

A study, concerning the Winkler foundations under uniformly distributed dynamic loads, has been proposed by Sun and Luo [6]. Other different numerical methods, based on the fast Fourier transform (FFT), have been more recently proposed for a greater efficiency of the dynamic response evaluation of the foundation beams.

The paper is made up of two distinct sections, both aimed to the determination of the transfer function. In the first section a forecasting model, deriving from the simplified one by Gazetas and Dobry [3], has been used (see paragraph 2). This model is able to ensure the necessary convergence between theoretical results and experimental data. In fact, it is particularly suitable in dealing with issues relating to high speed, as it is able to take into account the inertial and viscous effects generated by moving load speed. In the second section a FEM modeling by means of the ANSYS ${ }^{\circledR}$ code has been implemented.

This has allowed determining the transfer function in a more rigorous way than in the previous case, because all the superstructure's geometrical and material inhomogeneities have been considered, and consequently the convergence of the two methodologies has been evaluated.

\section{The mathematical model}

In Railway Engineering, to completely analyze the vehicle-superstructure interaction the equations of dynamic equilibrium of the individual components should be considered in accordance with the congruence conditions at their interfaces. The search of this solution, congruent to the examination of the couplings between the various structural parts (rails, ballast, sub-ballast, platform), is very expensive in terms of mathematical model implementation.

However, if some aspects of the in exercise phase are considered, such as the small displacement of the rail and its negligible mass with respect to the context, it is possible to decouple the various structural elements in favor of a static solution as long as the vehicle speed is low. In this case a further approximation is also to consider the bed surface reaction of static type.

However, this assumption implies the impossibility to compute in the global equilibrium balance the contribution, in terms of dynamic reaction, of the superstructure set in vibration during the train passage. Therefore, the difference between the reactions evaluated under static and dynamic conditions may be not negligible and this is truer as greater is the speed amplifying the vibrating effects.

Therefore, it is easy to understand that, in high-speed railway, to perform a reliable analysis of the dynamic interaction between vehicle and superstructure it is not possible to avoid an accurate assessment of the superstructure dynamic excitation, at the same time considering acceptable the assumptions of negligible rail mass and modest entity of its movements.

On the basis of these considerations the railway equilibrium equation assumes the following simplified form:

$E J \cdot \frac{\partial^{4}}{\partial x^{4}}[y(x, t)]-P \cdot \delta(x-c t)+f_{\mathrm{t}}(x, t)=0$,

where $E J$ is the railway's stiffness; $y(x, t)$ is the railway displacement; $x$ is the progressive abscissa; $t$ is the time; $P \cdot \delta(x-c t)$ is the external load that can be assimilated to a concentrated moving load with $c$ velocity without inertial effects; $\delta$ is the Dirac operator; $f_{\mathrm{t}}(x, t)$ is the ground response.

It should also be noted that in the design and maintenance of high-speed railway lines the stationary response of the system is more important than the transient phases.

The deformation of the railway, as a stationary response, counts:

$y=y(x-c t)$.

This assumption is equivalent to assume that an observer in motion on a reference system fixed with the moving load can see the track uniformly deformed, as occurs in the case of a boat in motion at constant speed, in absence of wave motion, for which there are always the same type and number of waves on bow.

To properly assess the ground reaction is necessary to consider its response in dynamic terms. Therefore, to evaluate the ground response, the rail could be outlined as a continuous beam on yielding supports characterized by a mass $M$, a dynamic stiffness $K$, and a damping factor $C$ with reference to the whole system consisting of sleepers, ballast, sub-ballast, and sub-base (see Fig. 1).

The $K$ and $C$ factors characterize the superstructure response, in particular great significance assumes the $C$ coefficient, which takes into account both the hysteretic damping of the sub-ballast asphalt concrete, and the radiation damping due to the imposition of the Sommerfeld's conditions (absence of infinitely distant source) [7] on the 


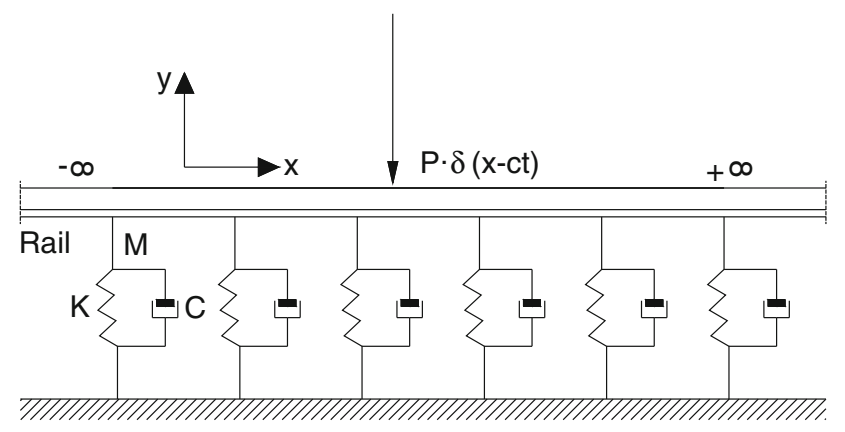

Fig. 1 Continuous beam on yielding supports

propagation of waves generated by the passage of moving load.

We can indicate, more generally, giving $h(t)$ as the extent of the response to the $x$ coordinate and to the $t$ time as the result of the starting condition $y=1$ at time $t=0$, the response of the superstructure returns to the rail, in the following way:

$f_{\mathrm{t}}(x, t)=\int_{-\infty}^{+\infty} y(x-c \tau) \cdot h(t-\tau) \cdot \mathrm{d} \tau$.

In order to better understand the meaning of the $h(t)$ function, it is possible to rewrite the Eq. (3) in the particular case in which $h(t)=k \cdot \delta(t)$, where $k$ is the foundation stiffness coefficient:

$f_{\mathrm{t}}(x, t)=\int_{-\infty}^{+\infty} y(x-c \tau) \cdot k \cdot \delta(t-\tau) \cdot \mathrm{d} \tau=k \cdot y(x-c \cdot t)$.

The Eq. (4) highlights a Winkler's reaction trend, with presence of the elastic component only, in the superstructure. In reality, as mentioned above, the moving load passage puts in oscillation both binary and superstructure, with the difference that while the inertial component of the track can be overlooked, the one of the superstructure assumes an appreciable entity.

The same happens for the viscous portion of the reaction that, consisting of two factors, material and geometry, and is important in the definition of the equilibrium equations.

For this reason, we must assign a most general possible expression to the $h(t)$ function. We also highlight that to find the solution of the railway equilibrium differential equation, we need to make use of the Fourier transform.

By introducing the coordinate:

$\xi=x-c t$,

that is, by acquiring a reference system in-built with the moving load, the Eq. (3) becomes: $f_{\mathrm{t}}(x, t)=\int_{-\infty}^{+\infty} y[\xi+c \cdot(t-\tau)] \cdot h(t-\tau) \cdot \mathrm{d} \tau$.

By considering Eqs. (5) and (6), the equilibrium Eq. (1) acquires the following form:

$E J \frac{\partial^{4}}{\partial \xi^{4}}[y(\xi)]+\int_{-\infty}^{+\infty} y[\xi+c \cdot(t-\tau)] \cdot h(t-\tau) \cdot \mathrm{d} \tau=P \cdot \delta(\xi)$,

from which, setting:

$\zeta=-c \cdot(t-\tau)$,

we obtain:

$E J \frac{\partial^{4}}{\partial \xi^{4}}[y(\xi)]+\frac{1}{c} \cdot \int_{-\infty}^{+\infty} y(\xi-\zeta) \cdot h\left(-\frac{\zeta}{c}\right) \cdot \mathrm{d} \zeta=P \cdot \delta(\xi)$.

Now we can apply to (9) the convolution theorem and the Fourier transform derivative one. By denominating $Y(\omega)$ the Fourier transform of the railway deformation and $H^{*}(c \omega)$ the conjugate of the transfer function $H(c \omega)$ which represents the superstructure (see Fig. 1), we achieve the following relation in the transformed domain:

$\mathrm{EJ} \omega^{4} \cdot Y(\omega)+H^{*}(c \omega) \cdot Y(\omega)=P$,

therefore:

$Y(\omega)=\frac{P}{E J \omega^{4}+H^{*}(c \omega)}$,

from which we obtain, definitively, by applying the inverse Fourier transform:

$y(\xi)=\frac{1}{2 \pi} \int_{-\infty}^{+\infty} \frac{P}{E J \omega^{4}+H^{*}(c \omega)} \cdot e^{i \cdot \omega \cdot \xi} \mathrm{d} \omega$.

The expression (12) represents the general form of the rail deformation under the action of a $P$ intensity moving load, which can evaluate the viscous and dynamic effects of the interaction between railway and superstructure.

The transfer function determination derives by fixing a mathematical oscillator model simulating the superstructure. The choice of this model depends on the accuracy of the results requested.

To examine the variability range of the transfer function, we have applied the simplified model, acquired by the technical literature [3] regarding the calculation of the vibrating foundations, which is conveniently converted to this case in point. In this schematization we assume, as a 


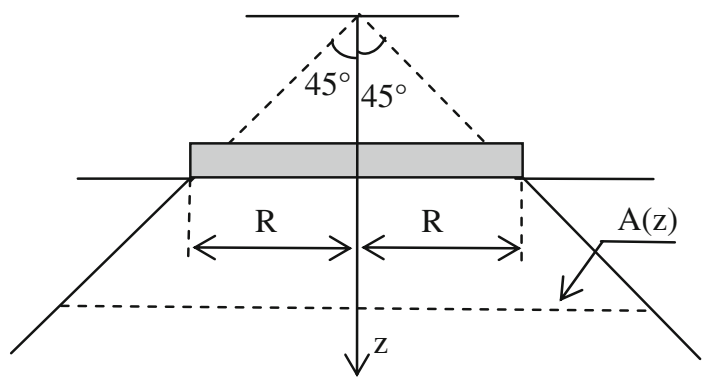

Fig. 2 Load scheme

superstructure oscillating part, a $R$ radius cone with generatrix at $45^{\circ}$ starting from the extremities of the circular area where the load is applied (see Fig. 2).

The evaluation of the system response in the frequencies domain can be expressed in the following way:

$\frac{\mathrm{d}}{\mathrm{d} z}\left(z^{2} \cdot \frac{\mathrm{d} U}{\mathrm{~d} z}\right)+z^{2} \cdot \frac{\omega^{2}}{V^{2}} \cdot U=0$,

where $U$ is the Fourier transform of the displacement considered, $V^{2}=E^{*} / \rho$ is the propagation velocity of the waves generated in the conical shaped continuous, $E^{*}$ is the equivalent Young modulus of the cone, and $\rho$ is the cone density.

The solution of the differential Eq. (13), by imposing the boundary condition of unitary displacement for $z$ equal to the $R$ radius and radiation to infinity, becomes the following:

$U(z, \omega)=z^{-\frac{1}{2}} \cdot H_{1 / 2}\left(\frac{\omega}{V} \cdot z\right)$,

where with $H_{1 / 2}$ we have indicated a Henkel function of second kind and of class $1 / 2$.

From the (14), by stating with $A$ the load applying area, it is possible to obtain the relation that relates in $z=R$ the load applied to the displacement in the frequencies domain, that is:

$F=-E^{*} \cdot A \cdot\left(\frac{\mathrm{d} U}{\mathrm{~d} Z}\right)_{z=R}=E^{*} \cdot A \cdot\left(\frac{1}{R}+i \cdot \frac{c}{V} \cdot \omega\right) \cdot U$.

From (15) we determine the transfer function that is evaluated:

$H(c \omega)=E^{*} \cdot A \cdot\left(\frac{1}{R}+i \cdot \frac{c}{V} \cdot \omega\right)$.

If we consider the vertical actions exchanged between rail and superstructure, the transfer function (16), even if obtained by choosing some simplifications, coincides with the function determined through the solution in closed form of an elastic half-space complete equations for the vertical oscillations on a $R$ radius disk [8].
It is evident that for the materials used in the construction of the railway superstructures it is plausible to assume a Poisson's ratio value $(v)$ less than $0.45[9,10]$. In agreement with what has been verified by several authors $[3,11]$ in the analysis of the vibrant foundations, therefore it is possible to assign, to the perturbation propagation speed $(V)$, the speed of the superstructure waves of volume $\left(V_{\mathrm{p}}\right)$, i.e.:

$V=V_{\mathrm{p}}=\sqrt{\frac{E \cdot(1-v)}{\rho \cdot(1+v) \cdot(1-2 v)}}$,

from which, recalling that $V^{2}=E^{*} / \rho$, results:

$E^{*}=\frac{E \cdot(1-v)}{(1+v) \cdot(1-2 v)}$.

It follows that $E^{*}$ exactly matches the edometric module value $\left(E_{\mathrm{d}}\right)$, valid in the case of impeded lateral deformations.

By replacing the conjugate of the (16) inside the (12) we obtain:

$y(\xi)=\frac{1}{2 \pi} \int_{-\infty}^{+\infty} \frac{P}{E J \omega^{4}+E^{*} \cdot A \cdot\left(\frac{1}{R}-i \cdot \frac{c}{V} \cdot \omega\right)} \cdot e^{i \cdot \omega \cdot \xi} \mathrm{d} \omega$.

In the (19) the function of the denominator tends to zero for $\omega \rightarrow 0$ and so satisfies the Lemma of Jordan, thus the integral can be calculated by the method of residuals. The expression (19) evaluates the superstructure stiffness and damping contributions.

It is important to specify that the adopted simplified model [3] assumes a linear relationship between the application frequency of the stress and the dynamic damping.

Therefore, to evaluate the damping effect, we have elaborated (19) by considering the hypothesis in which the stiffness contribution is null and the model parameters $(P$, $\left.E^{*}, A\right)$ are unitary. In this way, we have obtained the deformation expression held up under the hypothesis of a superstructure reactive only in viscous way. By applying the method of residuals and the Lemma of Jordan to this expression, we definitively obtain the trend of the rail deformation, that is:

$$
y(x)=\frac{P / E J}{\alpha}\left[-\frac{1}{2}+\frac{2}{3} \cdot e^{-\frac{\sqrt[3]{\alpha}}{2} \cdot x} \cdot \cos \left(\frac{\sqrt{3}}{2} \cdot \sqrt[3]{\alpha} \cdot x\right)\right]
$$

valid for $\mathrm{x} \geq 0$

$y(x)=\frac{P / E J}{\alpha}\left[\frac{1}{2}-\frac{e^{-\sqrt[3]{\alpha} \cdot x}}{3}\right]$ valid for $\mathrm{x}<0$

where $\alpha=c / V$.

We underline that the method put in practice respond only in a viscous way, so the equilibrium is guaranteed by 
only the viscous response in opposition to the deformation variation velocity.

To study the system response in presence of both elastic and viscose reactions, it is necessary to integrate (19) in general terms, which gives the following equation:

$y(\xi)=e^{-c \xi} \cdot[2 a \cos (d \xi)+2 b \operatorname{sen}(d \xi)]$,

in which the constants $a, b, c$, and $d$ are dependent on the denominator roots of the Fourier transform and the sign of the variable.

With reference to the mechanical and geometric values of a typical high-speed railway section adopted in Italy, the two previous approaches allow developing some general considerations. For example, in case of viscous only superstructure the (20) shows that this deformed is unsymmetrical with respect to the position of the load, being influenced by the direction of movement of the moving load.

For a greater clarification it may be useful to use the idea of a boat moving in a basin in absence of wave motion. In this case, the reaction trying to keep the water surface horizontal is only viscose, and an observer integral with the boat in motion can see ripples, generated from the direction of motion of the hull, as if they were stationary with respect to himself.

If the superstructure is reagent both in elastic and viscous mode, the processing of the (21) allows highlighting that even in this case the railway deformed is asymmetrical with respect to the position of the load, but the perturbation creates a peak of the negative bending moment with a lower value than in the purely viscous case. The analysis also shows that the perturbation is very rapidly damped due to the exponential factor present in the (21), which tends to cancel the solicitation after just a half-period.

From the designing point of view, the determination of the stresses, which are transferred reciprocally between the railway and the superstructure, assume great importance.

The reaction $R(\xi)$ from the superstructure on the rail can be obtained by applying the definition of the inverse Fourier transform, that is:

$R(\xi)=\frac{1}{2 \pi} \cdot \int_{-\infty}^{+\infty} Y(\omega) \cdot H^{*}(c \omega) \cdot e^{i \cdot \omega \cdot \xi} \mathrm{d} \omega$

which, considering the (11) gives:

$R(\xi)=\frac{1}{2 \pi} \cdot \int_{-\infty}^{+\infty} \frac{P \cdot H^{*}(c \omega)}{E J \omega^{4}+H^{*}(c \omega)} \cdot e^{i \cdot \omega \cdot \xi} \mathrm{d} \omega$.

The transfer function $H(c \omega)$ represents the action occurred by the bed surfaces on the railway and it therefore contains information concerning the geometrical and the mechanical characteristics of the embankment, of the ballast, and of the sub-ballast.

We have to calculate it, then, with a mean that lets these characteristics being represented as accurately as possible. To achieve this result we have analyzed the standard railway superstructure represented in Fig. 3.

The typical design parameters of Italian high-speed railway lines are the following.

Wagons:

- Mass per axis equal to $22.5 \mathrm{t}$;

- Design speed $250<V \leq 300 \mathrm{~km} / \mathrm{h}$;

- Average daily traffic 50,000-85,000 t;

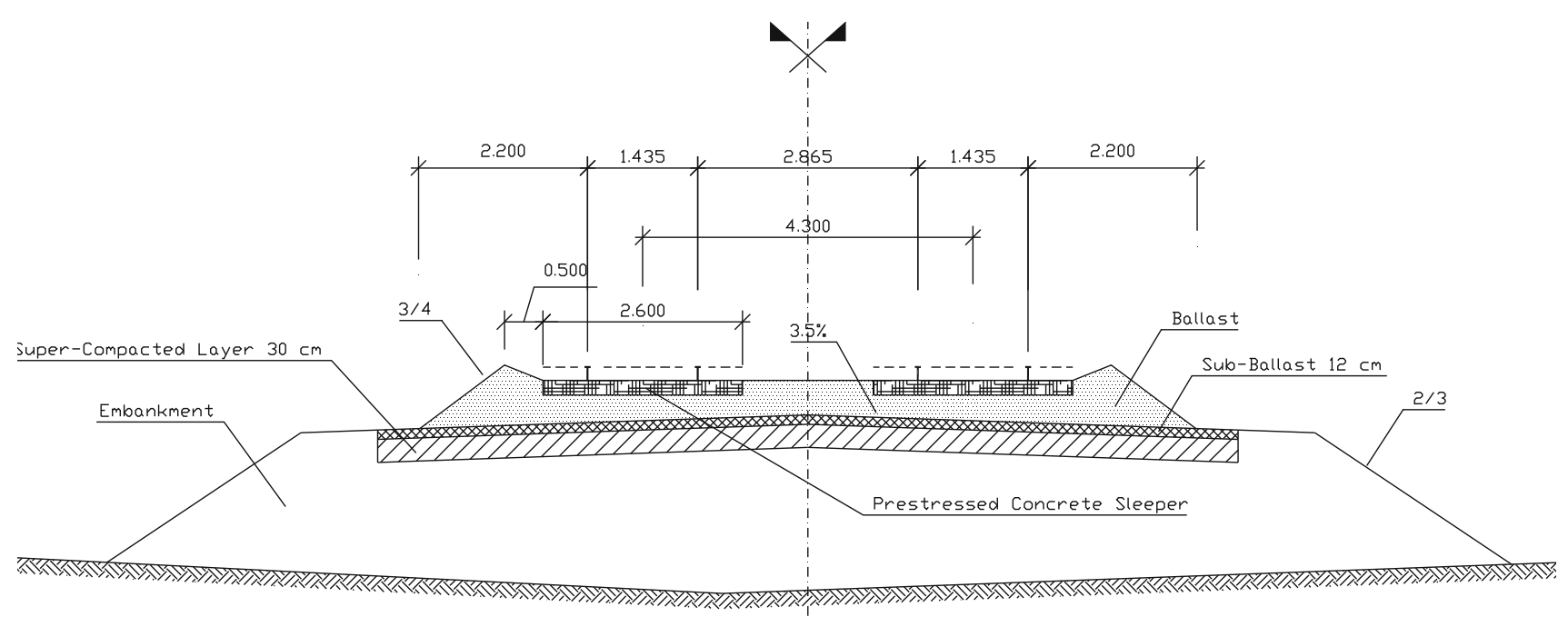

Fig. 3 The case of standard railway superstructure 


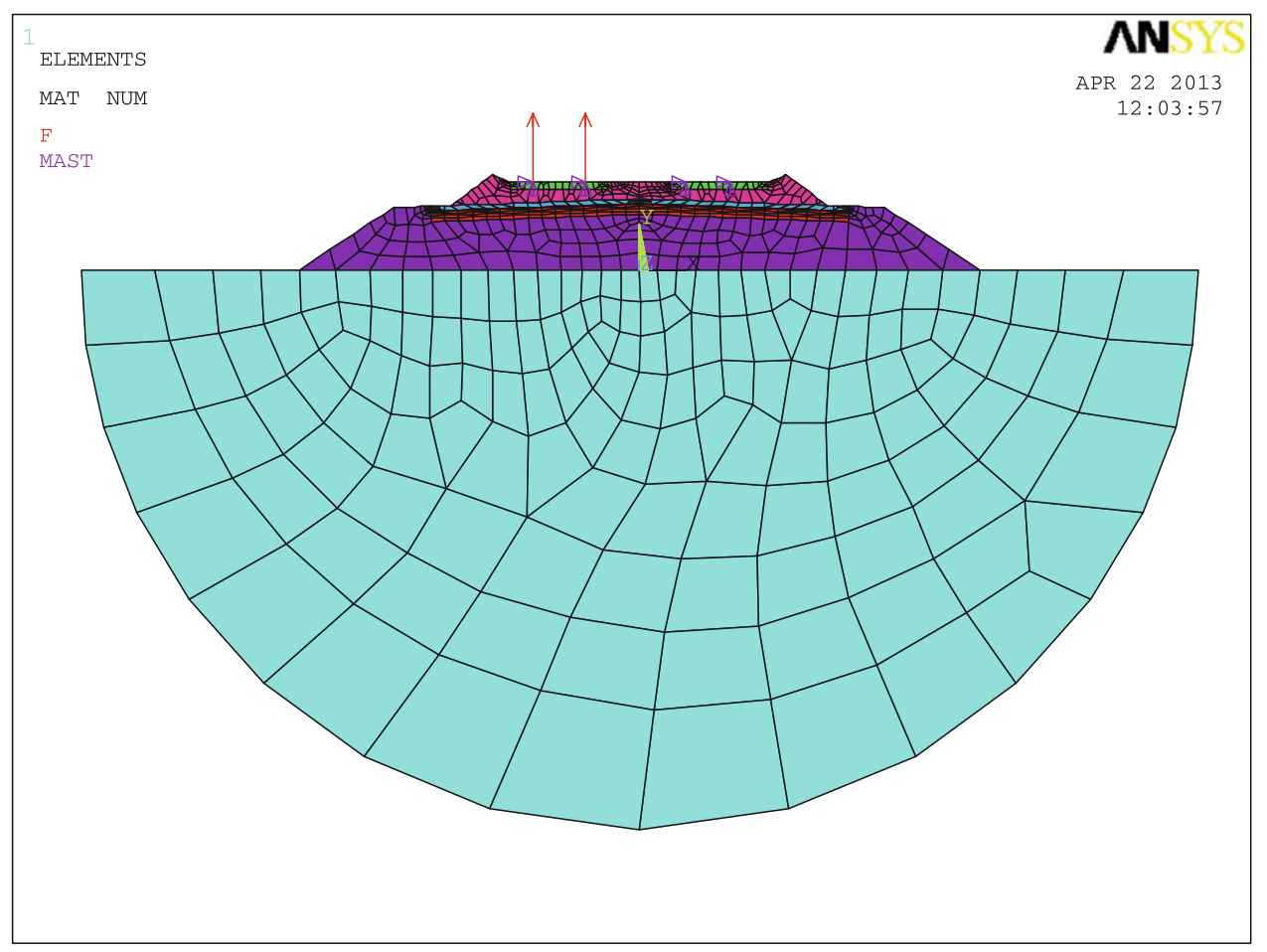

Fig. 4 FEM model implemented for the determination of the transfer function

- Dynamic overload coefficient:

- Normal 1.75;

- Exceptional 3.60.

Rails:

- Section 60 UC fiche 860-0 in steel 900A;

- Area section equal to $76.86 \mathrm{~cm}^{2}$;

- Height $177.0 \mathrm{~mm}$;

- $E J=6.415 E+06 \mathrm{Nm}^{2}$;

- Fixed in LWR with bars of $144.0 \mathrm{~m}$ and electric flash welding.

Sleepers in monobloc prestressed concrete:

- Mass 350-400 kg;

- Dimensions: $L=260.0 \mathrm{~cm} ; b=30.0 \mathrm{~cm} ; h=19.0 \mathrm{~cm}$;

- Inter-axis: $i=60.0 \mathrm{~cm}$.

Ballast realized with tough crushed stone, at a low abrasion coefficient level, coming from volcanic rocks (basalt) and metamorphic ones:

- Dimensions: $\phi_{\max }=6.0 \mathrm{~cm}$ and $\phi_{\min }=3.0 \mathrm{~cm}$;

- Thickness under railway $50.0 \mathrm{~cm}$;

- Headbed 50.0-60.0 cm;

- Crushed stone $K \geq 80.0 E+06 \mathrm{~N} / \mathrm{m}^{2}$;

- Resilient modulus $M_{\mathrm{r}} \geq 40.0 E+06 \mathrm{~N} / \mathrm{m}^{2}$.

Sub-ballast in asphalt concrete:

- Thickness $12.0 \mathrm{~cm}$;
- Absolute value of the complex modulus $\left|E^{*}\right| \geq 2,000.0 \mathrm{E}+06 \mathrm{~N} / \mathrm{m}^{2}$.

Soil:

- Super-compacted layer:

- Thickness $h=30.0 \mathrm{~cm}$;

- Deformation modulus $M_{\mathrm{d}} \geq 80.0 \mathrm{MPa}$

- Resilient modulus $M_{\mathrm{r}} \geq 160.0 \mathrm{E}+06 \mathrm{~N} / \mathrm{m}^{2}$;

- Embankment ${ }^{1}$ :

- Deformation modulus $M_{\mathrm{d}} \geq 40.0 \mathrm{MPa}$

- Resilient modulus $M_{\mathrm{r}} \geq 80.0 E+06 \mathrm{~N} / \mathrm{m}^{2}$;

- Embankment foundation:

- Deformation modulus $M_{\mathrm{d}} \geq 20.0 \mathrm{MPa}$;

- Resilient modulus $M_{\mathrm{r}} \geq 40.0 E+06 \mathrm{~N} / \mathrm{m}^{2}$.

Referring to this configuration, the $H$ function has been evaluated with the finite elements method and particularly, by resorting the ANSYS ${ }^{\circledR}$ code, we have discretized the structural continuum object of this study (see Fig. 4) through an appropriate mesh (see Fig. 5).

In the determination of the transfer function, the FEM modeling allows considering (unlike the previous model) all the superstructure geometric and material inhomogeneities.

\footnotetext{
1 These characteristics are also required when marginal materials are used for the construction of the embankment [12].
} 


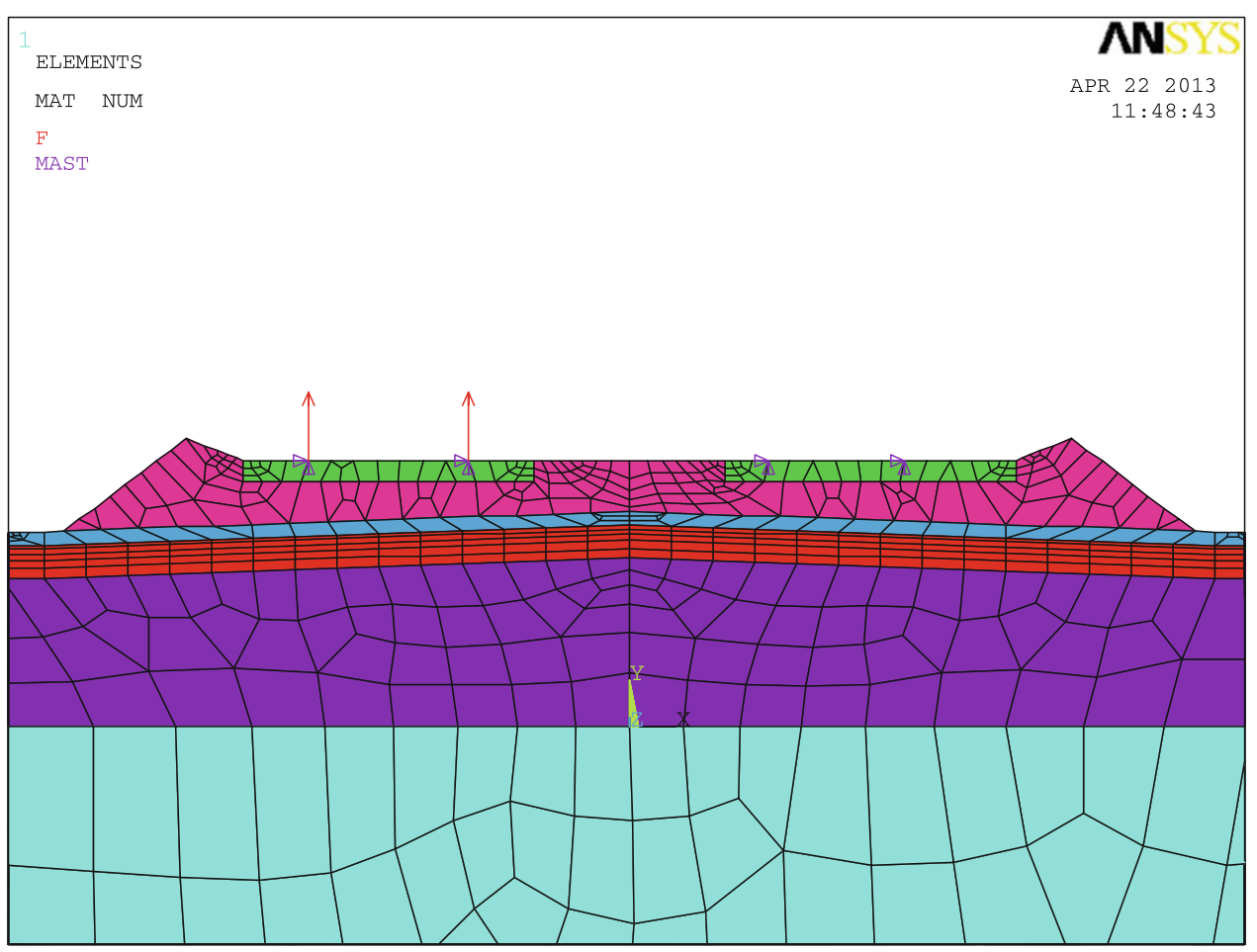

Fig. 5 Particular of the FEM model mesh

For this purpose, particular attention has been used in the simulation of the boundary conditions (radiation conditions or Sommerfeld's conditions [7]) that consider the damping due to the propagation of dynamic perturbation from the application area toward the infinite.

These conditions require a thorough knowledge of stratigraphy and composition of the sub-base. During the modeling phase linear dampers at the edges of the system (semicircle of Fig. 4) were placed along the $x$ and $y$ directions to absorb the energy transported up to that point by the waves generated by the applied load. These dampers are made up of ANSYS $^{\circledR}$ elements type COMBIN14 [13] characterized by $k=20.0 \mathrm{E}+06 \mathrm{~N} / \mathrm{m}$ and $c=6.0 \mathrm{E}+06 \mathrm{Ns} / \mathrm{m}$.

For the ground modeling (embankment foundation, embankment, super-compacted layer), sub-ballast, ballast, and sleepers, ANSYS ${ }^{\circledR}$ elements type PLANE42 characterized by the parameters shown in Table 1 have been used [13].

The determination of the transfer function has required the execution of a harmonic structural analysis in the frequencies field. The frequency interval scanned has been determined based on the speed of the moving load and of the geometrical and mechanical characteristics of the bed surfaces.

In this study the interval has been included between 0 and $400 \mathrm{~Hz}$, while the load has been adopted as equal to a unitary harmonic displacement applied, as shown in Fig. 4, in the connection point between rail and superstructure.
Table 1 Mechanical parameters of superstructure materials

\begin{tabular}{|c|c|c|c|}
\hline Description & $\begin{array}{l}\text { Modulus range } \\
\left(\mathrm{N} / \mathrm{m}^{2}\right)\end{array}$ & $\begin{array}{l}\text { Poisson's } \\
\text { ratio }\end{array}$ & $\begin{array}{l}\text { Density } \\
\left(\mathrm{kg} / \mathrm{m}^{3}\right)\end{array}$ \\
\hline $\begin{array}{l}\text { Embankment } \\
\text { foundation }^{\mathrm{a}}\end{array}$ & $4.00 \mathrm{E}+07$ & 0.40 & 1,800 \\
\hline Embankment $^{\mathrm{a}}$ & $\begin{array}{l}6.00 \mathrm{E}+07 \\
1.20 \mathrm{E}+08\end{array}$ & 0.40 & 1,800 \\
\hline $\begin{array}{l}\text { Super-compacted } \\
\text { layer }^{\mathrm{a}}\end{array}$ & $1.60 \mathrm{E}+08$ & 0.35 & 2,000 \\
\hline Sub-ballast ${ }^{\mathrm{b}}$ & $\begin{array}{l}1.00 \mathrm{E}+09 \\
5.00 \mathrm{E}+09\end{array}$ & 0.30 & 2,200 \\
\hline Ballast $^{\mathrm{a}}$ & $\begin{array}{l}3.50 \mathrm{E}+07 \\
5.00 \mathrm{E}+07\end{array}$ & 0.35 & 1,600 \\
\hline Sleepers ${ }^{\mathrm{c}}$ & $3.00 \mathrm{E}+10$ & 0.20 & 2,500 \\
\hline
\end{tabular}

${ }^{a}$ Resilient modulus

b Absolute value of asphalt concrete complex modulus

c Concrete Young modulus

\section{The superstructure frequency response}

The parameters on which we have illustrated the sensitivity's study are the following:

- Ballast thickness;

- Sub-ballast thickness;

- Super-compacted layer thickness;

- Embankment resilient modulus; 


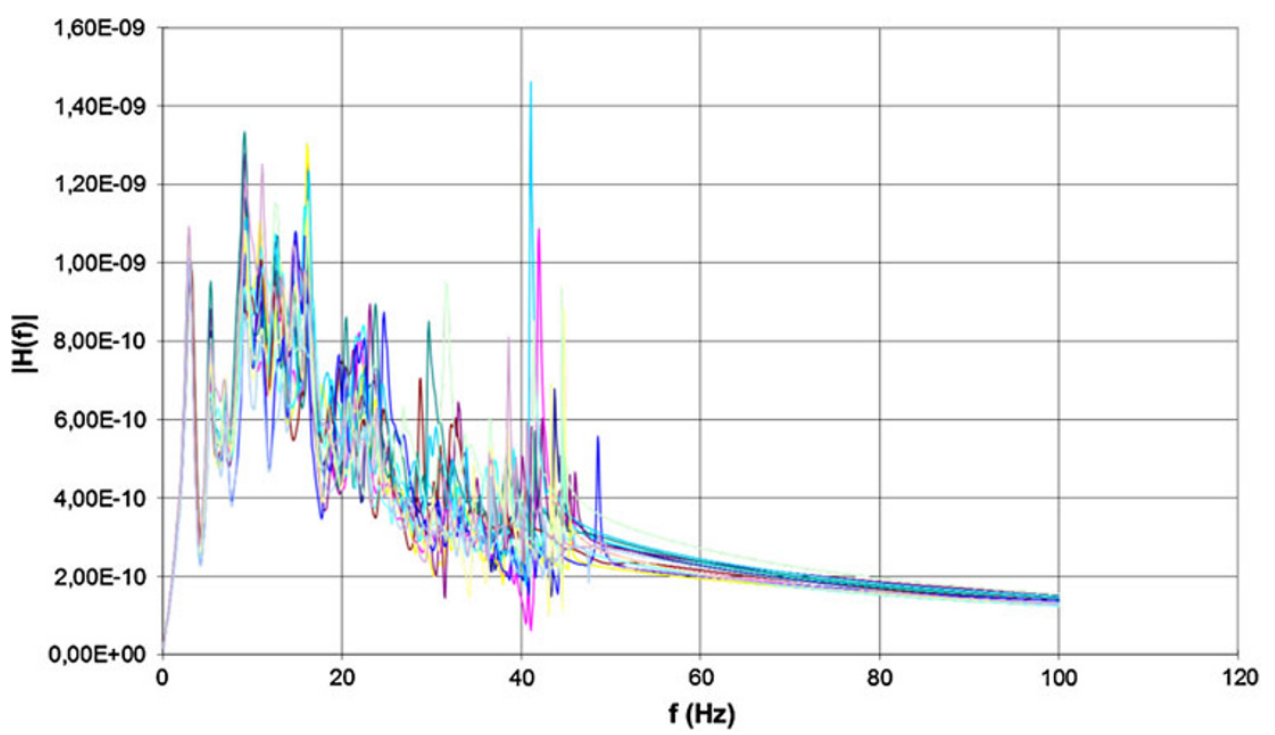

Fig. 6 Transfer function modulus trends $|H(f)|$

- Ballast resilient modulus;

- Sub-ballast complex modulus.

The variation range of this parameters has been included in the following limits:

- Ballast thickness: from 0.35 to $0.50 \mathrm{~m}$;

- Sub-ballast thickness: from 0.08 to $0.20 \mathrm{~m}$;

- Super-compacted layer thickness: from 0.25 to $0.45 \mathrm{~m}$;

- Embankment resilient modulus: from $6.0 \mathrm{E}+07$ to $1.2 \mathrm{E}+08 \mathrm{~N} / \mathrm{m}^{2}$;

- Ballast resilient modulus: from $3.5 \mathrm{E}+07$ to $5.0 \mathrm{E}+07 \mathrm{~N} / \mathrm{m}^{2}$;

- Sub-ballast complex modulus ${ }^{2}$ [14]: from $1.00 \mathrm{E}+09$ to $5.0 \mathrm{E}+09 \mathrm{~N} / \mathrm{m}^{2}$.

Figure 6 shows the transfer function trends $H(f)$, expressed as modulus value since the harmonic analysis gives complex results, by varying frequency and defined parameters inside the limits above.

The transfer function obtained by numerical simulation represents, in the real part, the dynamic stiffness and, in the complex part, the superstructure dynamic damping.

We can draw the following conclusions from the general analysis of the results:

- Above $100 \mathrm{~Hz}$, in every analyzed cases, the bed surfaces respond in a very flexible way, since the

${ }^{2}$ In the calculations concerning the frequency interval between 0 and $60 \mathrm{~Hz}$ for the sub-ballast complex modulus, we have taken the highest value of $2.0 \mathrm{E}+09 \mathrm{~N} / \mathrm{m}^{2}$, at a fixed temperature of $10{ }^{\circ} \mathrm{C}$ and invariable for the frequency, by serving the security in the design determinations, since from this approximation descends a higher stress state. The transfer function $H(f)$, for frequency values above $60 \mathrm{~Hz}$, tends to zero and the modulus does not condition the structural response of the system.

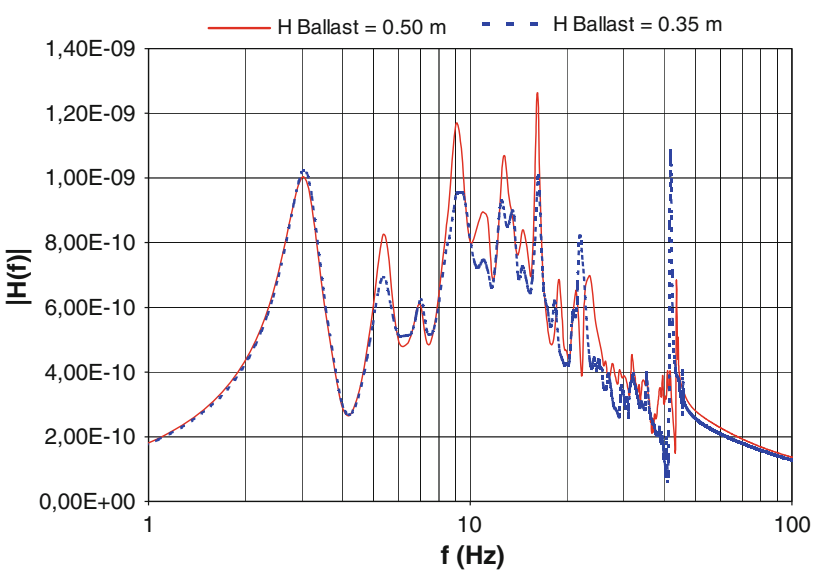

Fig. 7 Trends of $|H(f)|$ by varying the ballast thickness

$H(f)$ tends swiftly to zero and so the bed surfaces turn out to be lightly loaded, while the rail grasps all the stress;

- For frequencies under $5 \mathrm{~Hz}$, the responses of all the analyzed cases match together, while the more marked differentiations concentrate on the frequencies range between 10 and $50 \mathrm{~Hz}$.

Subsequently, we have examined in Figs. 7, 8, 9, 10, 11 and 12 the different trends of the transfer functions $H(f)$, by specifically analyzing the individual parameters.

Figure 7 has pointed out the trend of transfer function modulus $H(f)$ by varying frequency and ballast thickness. The data show that a narrow ballast thickness $(H=0.35 \mathrm{~m})$ gives a less rigid response, with the exception of the last peak.

Figure 8 shows the analysis responses in the case of the variation of the sub-ballast thickness, in terms of transfer 


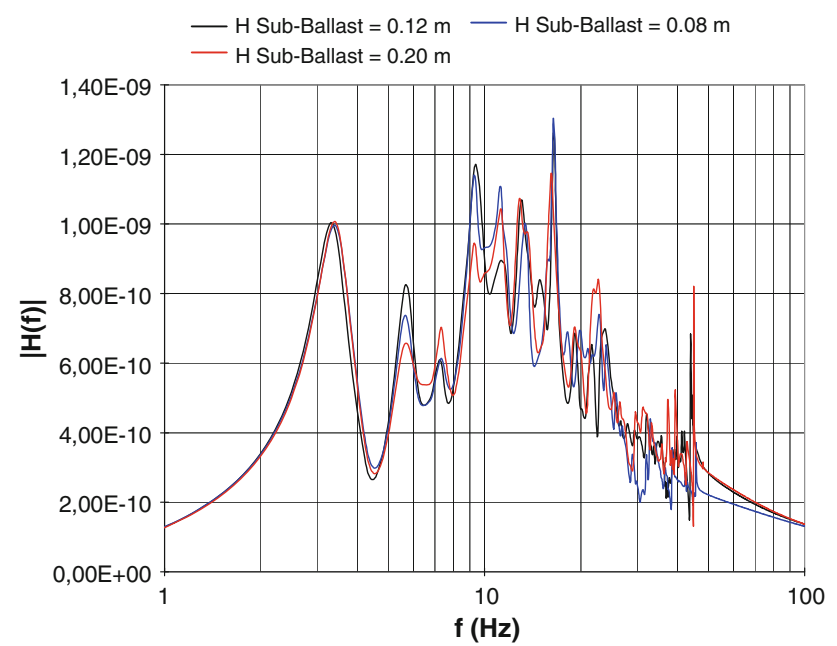

Fig. 8 Trends of the $|H(f)|$ by varying the sub-ballast thickness

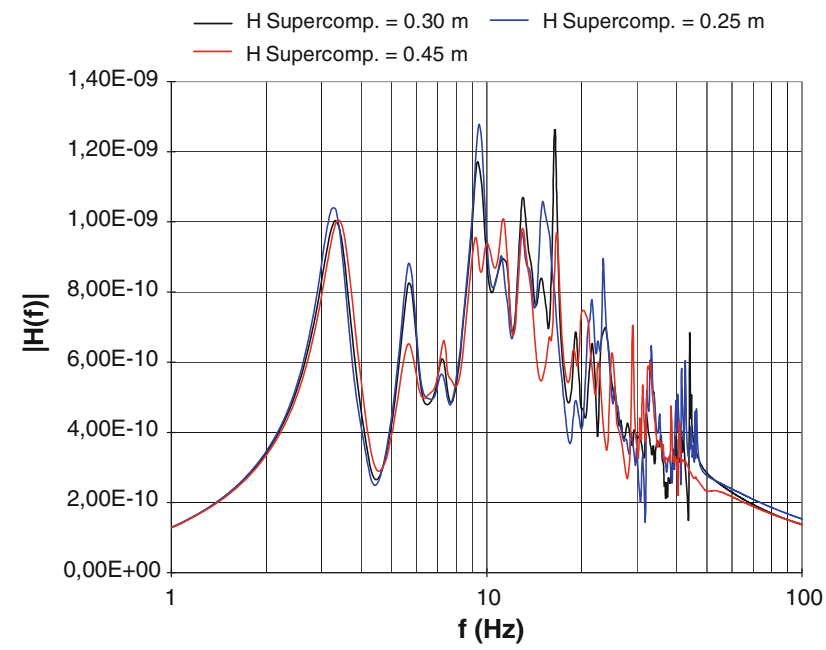

Fig. 9 Trends of $|H(f)|$ by varying the super-compacted layer thickness

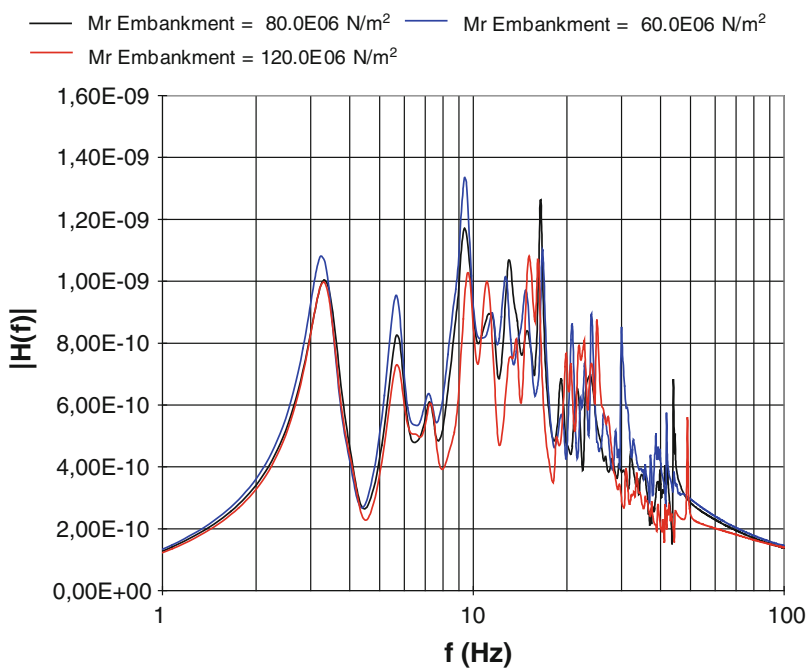

Fig. 10 Trends of the $|H(f)|$ by varying the embankment $M_{\mathrm{r}}$ modulus

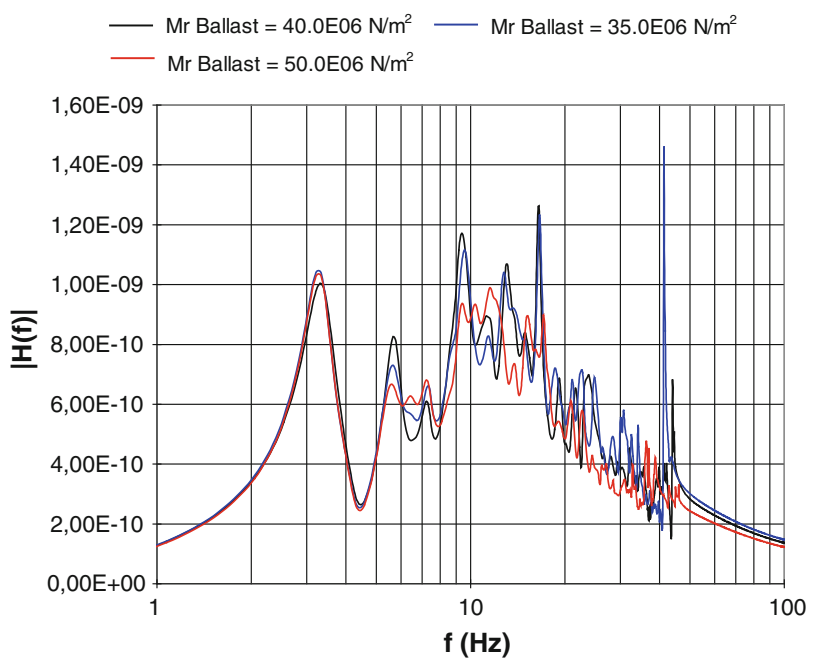

Fig. 11 Trends of the $|H(f)|$ by varying the ballast $M_{\mathrm{r}}$ modulus

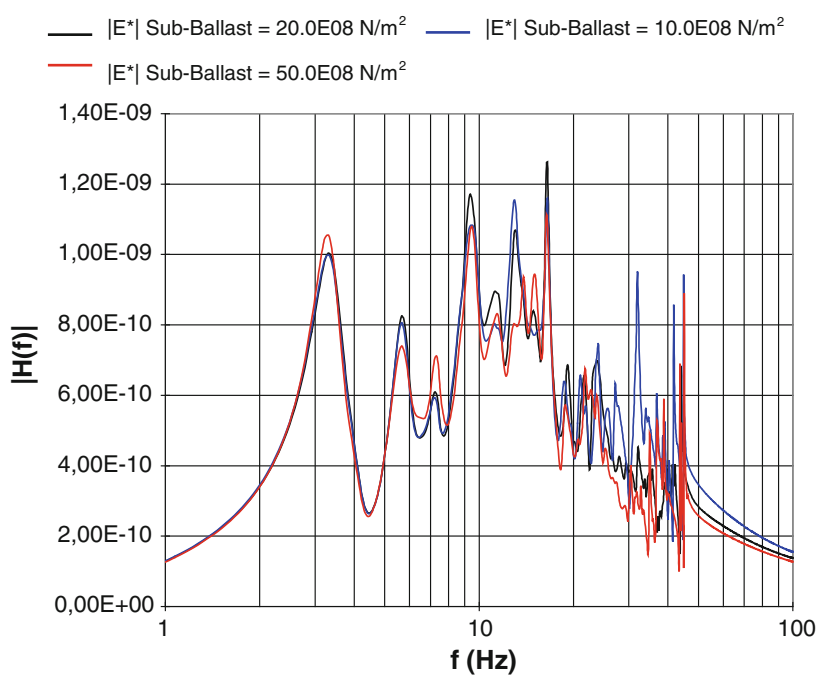

Fig. 12 Trends of the $|H(f)|$ by varying the sub-ballast $\left|E^{*}\right|$ modulus

function modulus. Also in this case, at a smaller thickness value corresponds a less rigid response, even if the values for frequency under $5 \mathrm{~Hz}$ have the same behavior.

Figure 9 shows the results obtained from the variation of the super-compacted layer thickness. We can note that, unlike the previous cases, an increase of the layer thickness allows to obtain a less rigid general response of the bed surfaces. Indeed we can observe how at the lowest frequencies the transfer function trends, for $H=0.25 \mathrm{~m}$ and $H=0.30 \mathrm{~m}$ (standard), are nearly superimposable, even if the tendency toward a stiffening, for thickness reduction, is clear. For the highest frequency values, the response for $H=0.30 \mathrm{~m}$ has a general more rigid behavior than the other cases.

Figure 10 shows the results obtained for a variation of the embankment resilient modulus. The diagram clearly 
Table 2 Maxima and minima displacement values for the different combinations

\begin{tabular}{|c|c|c|c|c|c|c|c|c|c|c|}
\hline \multirow[t]{3}{*}{ No. } & \multirow{3}{*}{$\begin{array}{l}H \text { ballast } \\
(\mathrm{m})\end{array}$} & \multirow{3}{*}{$\begin{array}{l}H \text { sub- } \\
\text { ballast (m) }\end{array}$} & \multirow{3}{*}{$\begin{array}{l}H \text { supercomp. } \\
\text { (m) }\end{array}$} & \multirow{3}{*}{$\begin{array}{l}M_{\mathrm{r}} \\
\text { embankment } \\
\left(\mathrm{N} / \mathrm{m}^{2}\right)^{\mathrm{a}}\end{array}$} & \multirow{3}{*}{$\begin{array}{l}M_{\mathrm{r}} \text { ballast } \\
\left(\mathrm{N} / \mathrm{m}^{2}\right)^{\mathrm{a}}\end{array}$} & \multirow{3}{*}{$\begin{array}{l}\mid E^{* \mid} \text { sub- } \\
\text { ballast } \\
\left(\mathrm{N} / \mathrm{m}^{2}\right)^{\mathrm{b}}\end{array}$} & \multicolumn{4}{|c|}{ Displacements } \\
\hline & & & & & & & \multicolumn{2}{|l|}{ Min. } & \multicolumn{2}{|l|}{ Max. } \\
\hline & & & & & & & $X(\mathrm{~m})$ & $D Y(\mathrm{~m})$ & $X(\mathrm{~m})$ & $D Y(\mathrm{~m})$ \\
\hline 1 & 0.50 & 0.12 & 0.30 & $8.00 \mathrm{E}+07$ & $4.00 \mathrm{E}+07$ & $2.00 \mathrm{E}+09$ & -0.625 & $-1.72 \mathrm{E}-06$ & 1.667 & $8.05 \mathrm{E}-07$ \\
\hline 2 & 0.35 & 0.12 & 0.30 & $8.00 \mathrm{E}+07$ & $4.00 \mathrm{E}+07$ & $2.00 \mathrm{E}+09$ & -0.625 & $-1.55 \mathrm{E}-06$ & 4.167 & $7.47 \mathrm{E}-07$ \\
\hline 3 & 0.50 & 0.08 & 0.30 & $8.00 \mathrm{E}+07$ & $4.00 \mathrm{E}+07$ & $2.00 \mathrm{E}+09$ & -0.625 & $-1.39 \mathrm{E}-06$ & 3.125 & $8.31 \mathrm{E}-07$ \\
\hline 4 & 0.50 & 0.20 & 0.30 & $8.00 \mathrm{E}+07$ & $4.00 \mathrm{E}+07$ & $2.00 \mathrm{E}+09$ & -0.625 & $-1.72 \mathrm{E}-06$ & 1.875 & $8.30 \mathrm{E}-07$ \\
\hline 5 & 0.50 & 0.12 & 0.25 & $8.00 \mathrm{E}+07$ & $4.00 \mathrm{E}+07$ & $2.00 \mathrm{E}+09$ & -0.625 & $-1.71 \mathrm{E}-06$ & 1.667 & $9.28 \mathrm{E}-07$ \\
\hline 6 & 0.50 & 0.12 & 0.45 & $800 \mathrm{E}+07$ & $4.00 \mathrm{E}+07$ & $200 \mathrm{E}+09$ & -0.625 & $-1.54 \mathrm{E}-06$ & 2.292 & $9.21 \mathrm{E}-07$ \\
\hline 7 & 0.50 & 0.12 & 0.30 & $6.00 \mathrm{E}+07$ & $4.00 \mathrm{E}+07$ & $2.00 \mathrm{E}+09$ & -0.625 & $-1.87 \mathrm{E}-06$ & 1.875 & $9.82 \mathrm{E}-07$ \\
\hline 8 & 0.50 & 0.12 & 0.30 & $1.20 \mathrm{E}+08$ & $4.00 \mathrm{E}+07$ & $2.00 \mathrm{E}+09$ & -0.625 & $-1.37 \mathrm{E}-06$ & 3.333 & $8.30 \mathrm{E}-07$ \\
\hline 9 & 0.50 & 0.12 & 0.30 & $8.00 \mathrm{E}+07$ & $3.50 \mathrm{E}+07$ & $2.00 \mathrm{E}+09$ & -0.625 & $-1.80 \mathrm{E}-06$ & 1.458 & $8.87 \mathrm{E}-07$ \\
\hline 10 & 0.50 & 0.12 & 0.30 & $8.00 \mathrm{E}+07$ & $5.00 \mathrm{E}+07$ & $2.00 \mathrm{E}+09$ & -0.625 & $-1.55 \mathrm{E}-06$ & 2.083 & $7.35 \mathrm{E}-07$ \\
\hline 11 & 0.50 & 0.12 & 0.30 & $8.00 \mathrm{E}+07$ & $4.00 \mathrm{E}+07$ & $1.00 \mathrm{E}+09$ & -0.625 & $-2.05 \mathrm{E}-06$ & 1.250 & $1.07 \mathrm{E}-06$ \\
\hline 12 & 0.50 & 0.12 & 0.30 & $8.00 \mathrm{E}+07$ & $4.00 \mathrm{E}+07$ & $5.00 \mathrm{E}+09$ & -0.625 & $-1.56 \mathrm{E}-06$ & 4.167 & $6.97 \mathrm{E}-07$ \\
\hline 13 & 0.50 & 0.20 & 0.45 & $1.20 \mathrm{E}+08$ & $5.00 \mathrm{E}+07$ & $5.00 \mathrm{E}+09$ & -0.625 & $-1.44 \mathrm{E}-06$ & 3.333 & $7.22 \mathrm{E}-07$ \\
\hline 14 & 0.35 & 0.08 & 0.25 & $6.00 \mathrm{E}+07$ & $3.50 \mathrm{E}+07$ & $1.00 \mathrm{E}+09$ & -0.625 & $-1.59 \mathrm{E}-06$ & 2.083 & $9.09 \mathrm{E}-07$ \\
\hline
\end{tabular}

${ }^{a}$ Resilient modulus

b Absolute value of complex modulus

Table 3 Maxima and minima bending moment values for the different combinations

\begin{tabular}{|c|c|c|c|c|c|c|c|c|c|c|}
\hline \multirow[t]{3}{*}{ No. } & \multirow{3}{*}{$\begin{array}{l}H \text { ballast } \\
(\mathrm{m})\end{array}$} & \multirow{3}{*}{$\begin{array}{l}H \text { sub- } \\
\text { ballast (m) }\end{array}$} & \multirow{3}{*}{$\begin{array}{l}H \text { supercomp. } \\
(\mathrm{m})\end{array}$} & \multirow{3}{*}{$\begin{array}{l}M_{\mathrm{r}} \\
\text { embankment } \\
\left(\mathrm{N} / \mathrm{m}^{2}\right)^{\mathrm{a}}\end{array}$} & \multirow{3}{*}{$\begin{array}{l}M_{\mathrm{r}} \text { ballast } \\
\left(\mathrm{N} / \mathrm{m}^{2}\right)^{\mathrm{a}}\end{array}$} & \multirow{3}{*}{$\begin{array}{l}\left|E^{*}\right| \text { sub- } \\
\text { ballast } \\
\left(\mathrm{N} / \mathrm{m}^{2}\right)^{\mathrm{b}}\end{array}$} & \multicolumn{4}{|c|}{ Bending moment } \\
\hline & & & & & & & \multicolumn{2}{|l|}{ Min. } & \multicolumn{2}{|l|}{ Max. } \\
\hline & & & & & & & $X(\mathrm{~m})$ & $M(\mathrm{Nm})$ & $X(\mathrm{~m})$ & $M(\mathrm{Nm})$ \\
\hline 1 & 0.50 & 0.12 & 0.30 & $8.00 \mathrm{E}+07$ & $4.00 \mathrm{E}+07$ & $2.00 \mathrm{E}+09$ & -0.625 & -284.294 & -2.083 & 224.752 \\
\hline 2 & 0.35 & 0.12 & 0.30 & $8.00 \mathrm{E}+07$ & $4.00 \mathrm{E}+07$ & $2.00 \mathrm{E}+09$ & -0.625 & -266.121 & -2.083 & 204.650 \\
\hline 3 & 0.50 & 0.08 & 0.30 & $8.00 \mathrm{E}+07$ & $4.00 \mathrm{E}+07$ & $2.00 \mathrm{E}+09$ & -0.625 & -230.611 & -1.875 & 178.813 \\
\hline 4 & 0.50 & 0.20 & 0.30 & $8.00 \mathrm{E}+07$ & $4.00 \mathrm{E}+07$ & $2.00 \mathrm{E}+09$ & -0.625 & -280.968 & -2.083 & 224.808 \\
\hline 5 & 0.50 & 0.12 & 0.25 & $8.00 \mathrm{E}+07$ & $4.00 \mathrm{E}+07$ & $2.00 \mathrm{E}+09$ & -0.625 & -272.945 & -2.083 & 210.056 \\
\hline 6 & 0.50 & 0.12 & 0.45 & $8.00 \mathrm{E}+07$ & $4.00 \mathrm{E}+07$ & $2.00 \mathrm{E}+09$ & -0.625 & -251.300 & -2.083 & 196.433 \\
\hline 7 & 0.50 & 0.12 & 0.30 & $6.00 \mathrm{E}+07$ & $4.00 \mathrm{E}+07$ & $2.00 \mathrm{E}+09$ & -0.625 & -299.059 & -2.083 & 245.444 \\
\hline 8 & 0.50 & 0.12 & 0.30 & $1.20 \mathrm{E}+08$ & $4.00 \mathrm{E}+07$ & $2.00 \mathrm{E}+09$ & -0.625 & -227.942 & -1.875 & 165.731 \\
\hline 9 & 0.50 & 0.12 & 0.30 & $8.00 \mathrm{E}+07$ & $3.50 \mathrm{E}+07$ & $2.00 \mathrm{E}+09$ & -0.625 & -287.945 & -2.083 & 222324 \\
\hline 10 & 0.50 & 0.12 & 0.30 & $8.00 \mathrm{E}+07$ & $5.00 \mathrm{E}+07$ & $2.00 \mathrm{E}+09$ & -0.625 & -265.610 & -1.875 & 212.066 \\
\hline 11 & 0.50 & 0.12 & 0.30 & $8.00 \mathrm{E}+07$ & $4.00 \mathrm{E}+07$ & $1.00 \mathrm{E}+09$ & -0.625 & -320.799 & -2.292 & 259.074 \\
\hline 12 & 0.50 & 0.12 & 0.30 & $8.00 \mathrm{E}+07$ & $4.00 \mathrm{E}+07$ & $5.00 \mathrm{E}+09$ & -0.625 & -266.102 & -2.083 & 204.536 \\
\hline 13 & 0.50 & 0.20 & 0.45 & $1.20 \mathrm{E}+08$ & $5.00 \mathrm{E}+07$ & $5.00 \mathrm{E}+09$ & -0.625 & -249.878 & -2.083 & 189.683 \\
\hline 14 & 0.35 & 0.08 & 0.25 & $6.00 \mathrm{E}+07$ & $3.50 \mathrm{E}+07$ & $1.00 \mathrm{E}+09$ & -0.625 & -261.954 & -1.875 & 222.061 \\
\hline
\end{tabular}

${ }^{a}$ Resilient modulus

b Absolute value of complex modulus

shows how with an increase of the soil quality, that is, with an increase of its resilient modulus, corresponds a less rigid general response, both at the lowest frequencies between 0 and $10 \mathrm{~Hz}$, and at the highest ones. In addition, we can note that the last peak of the curve in red color shifts toward higher frequencies and shows lower extent than the other two cases.

Figure 11 shows the data connected to the variation of the ballast resilient modulus. We notice, in this case, how the three responses are superimposable, with the exclusion 
Table 4 Maxima and minima response values for the different combinations

\begin{tabular}{|c|c|c|c|c|c|c|c|c|c|c|}
\hline \multirow[t]{3}{*}{ No. } & \multirow{3}{*}{$\begin{array}{l}H \text { ballast } \\
(\mathrm{m})\end{array}$} & \multirow{3}{*}{$\begin{array}{l}H \text { sub- } \\
\text { ballast } \\
(\mathrm{m})\end{array}$} & \multirow{3}{*}{$\begin{array}{l}H \text { supercomp. } \\
\text { (m) }\end{array}$} & \multirow{3}{*}{$\begin{array}{l}M_{\mathrm{r}} \\
\text { embankment } \\
\left(\mathrm{N} / \mathrm{m}^{2}\right)^{\mathrm{a}}\end{array}$} & \multirow{3}{*}{$\begin{array}{l}M_{\mathrm{r}} \text { ballast } \\
\left(\mathrm{N} / \mathrm{m}^{2}\right)^{\mathrm{a}}\end{array}$} & \multirow{3}{*}{$\begin{array}{l}\left|E^{*}\right| \text { sub- } \\
\text { ballast } \\
\left(\mathrm{N} / \mathrm{m}^{2}\right)^{\mathrm{b}}\end{array}$} & \multicolumn{4}{|c|}{ Response } \\
\hline & & & & & & & \multicolumn{2}{|l|}{ Min. } & \multicolumn{2}{|l|}{ Max. } \\
\hline & & & & & & & $X(\mathrm{~m})$ & $R(\mathrm{~N})$ & $X(\mathrm{~m})$ & $R(\mathrm{~N})$ \\
\hline 1 & 0.50 & 0.12 & 0.30 & $8.00 \mathrm{E}+07$ & $4.00 \mathrm{E}+07$ & $2.00 \mathrm{E}+09$ & -1.875 & $-4,002.509$ & -0.417 & $5,915.723$ \\
\hline 2 & 0.35 & 0.12 & 0.30 & $8.00 \mathrm{E}+07$ & $4.00 \mathrm{E}+07$ & $2.00 \mathrm{E}+09$ & -1.875 & $-4,032.182$ & -0.417 & $5,984.580$ \\
\hline 3 & 0.50 & 0.08 & 0.30 & $8.00 \mathrm{E}+07$ & $4.00 \mathrm{E}+07$ & $2.00 \mathrm{E}+09$ & -1.875 & $-3,615.824$ & -0.417 & $5,651.975$ \\
\hline 4 & 0.50 & 0.20 & 0.30 & $8.00 \mathrm{E}+07$ & $4.00 \mathrm{E}+07$ & $2.00 \mathrm{E}+09$ & -2.083 & $-3,962.010$ & -0.417 & $5,738.226$ \\
\hline 5 & 0.50 & 0.12 & 0.25 & $8.00 \mathrm{E}+07$ & $4.00 \mathrm{E}+07$ & $2.00 \mathrm{E}+09$ & -1.875 & $-3,662.011$ & -0.417 & $5,648.867$ \\
\hline 6 & 0.50 & 0.12 & 0.45 & $8.00 \mathrm{E}+07$ & $4.00 \mathrm{E}+07$ & $2.00 \mathrm{E}+09$ & -1.875 & $-3,792.344$ & -0.417 & $5,638.877$ \\
\hline 7 & 0.50 & 0.12 & 0.30 & $6.00 \mathrm{E}+07$ & $4.00 \mathrm{E}+07$ & $2.00 \mathrm{E}+09$ & -2.083 & $-4,242.639$ & -0.417 & $5,934.945$ \\
\hline 8 & 0.50 & 0.12 & 0.30 & $1.20 \mathrm{E}+08$ & $4.00 \mathrm{E}+07$ & $2.00 \mathrm{E}+09$ & -1.875 & $-3,341.496$ & -0.417 & $5,507.585$ \\
\hline 9 & 0.50 & 0.12 & 0.30 & $8.00 \mathrm{E}+07$ & $3.50 \mathrm{E}+07$ & $2.00 \mathrm{E}+09$ & -2.083 & $-3,844.206$ & -0.417 & $5,714.466$ \\
\hline 10 & 0.50 & 0.12 & 0.30 & $8.00 \mathrm{E}+07$ & $5.00 \mathrm{E}+07$ & $2.00 \mathrm{E}+09$ & -1.875 & $-4,230.597$ & -0.417 & $6,085.297$ \\
\hline 11 & 0.50 & 0.12 & 0.30 & $8.00 \mathrm{E}+07$ & $4.00 \mathrm{E}+07$ & $1.00 \mathrm{E}+09$ & -2.083 & $-4,129.349$ & -0.625 & $5,758.841$ \\
\hline 12 & 0.50 & 0.12 & 0.30 & $8.00 \mathrm{E}+07$ & $4.00 \mathrm{E}+07$ & $5.00 \mathrm{E}+09$ & -1.875 & $-4,056.394$ & -0.417 & $6,017.052$ \\
\hline 13 & 0.50 & 0.20 & 0.45 & $1.20 \mathrm{E}+08$ & $5.00 \mathrm{E}+07$ & $5.00 \mathrm{E}+09$ & -1.875 & $-3,576.307$ & -0.417 & $5,454.509$ \\
\hline 14 & 0.35 & 0.08 & 0.25 & $6.00 \mathrm{E}+07$ & $3.50 \mathrm{E}+07$ & $1.00 \mathrm{E}+09$ & -1.875 & $-4,337.428$ & -0.417 & $6,079.627$ \\
\hline
\end{tabular}

${ }^{a}$ Resilient modulus

b Absolute value of complex modulus

of some peaks at the highest frequencies in the case of the modulus lowest value.

Finally, Fig. 12 describes the responses in the case of the variations of the sub-ballast layer complex modulus. In this case the general response is little conditioned by the variation of this parameter and the most rigid behavior is showed at the lowest modulus value, especially at the highest frequencies.

The analysis developed with the FEM modeling has also allowed highlighting that the hypothesis adopted by using the simplified model (i.e., the hypothesis of linear relationship between the stress application frequency and the dynamic damping) is valid for frequencies higher than $75 \mathrm{~Hz}$ or at high speeds $(>250 \mathrm{~km} / \mathrm{h})$.

\section{The general response of the system}

Having defined the frequency response of the bed surfaces, it is possible to evaluate the system response in its totality (railway and superstructure). The structure behavior has been evaluated in terms of track displacement, maximum and minimum bending moment, and total load that the rail transfers to the bed surfaces. These values are sufficient to estimate the stress to which the various structural components are subjected and thus to evaluate the influence that the mechanical and geometrical parameters have on the superstructure performance.

For this purpose we have analyzed 14 value combinations of the mechanical and geometrical parameters involved, obtaining the results summarized in Tables 2, 3, and 4 in which maxima and minima values of displacements, bending moment, and bed surface response are reported, while in Fig. 13a-c has been reported an example of the bending moment deformation trend and the response by varying the abscissa.

From the analysis of Tables 2, 3, and 4 we deduce that the most positive result, that is the one which guarantees the lower stress level both in terms of bending moment and of load on the bed surfaces, is obtained by the combination No. 8 in which, compared with the case stated as the standard (No. 1) and used today in the Italian railway high speed, the modulus of the embankment has been increased up to $1.2 \mathrm{E}+08 \mathrm{~N} / \mathrm{m}^{2}$.

In the combination No. 13 we obtain a nearly equal result increasing the sub-ballast thickness up to $0.20 \mathrm{~m}$. We can not obtain an improvement just like that obtained in the combination No. 6, even if we increase the layer thickness of the super-compacted layer of the embankment.

Moreover, by increasing the ballast thickness from 0.35 to $0.50 \mathrm{~m}$ we do not obtain a substantial improvement in terms of stress, while going from the combination No. 2 to the combination No. 6 , and thus increasing the supercompacted layer thickness we have an improvement of the reaction on the bed surface of around $10 \%$.

Considering the combinations Nos. 3, 4, 11, and 12 we can note how in the first two cases there are not substantial variations in the general response, while in the other two cases we can note how at an increase of the transfer 

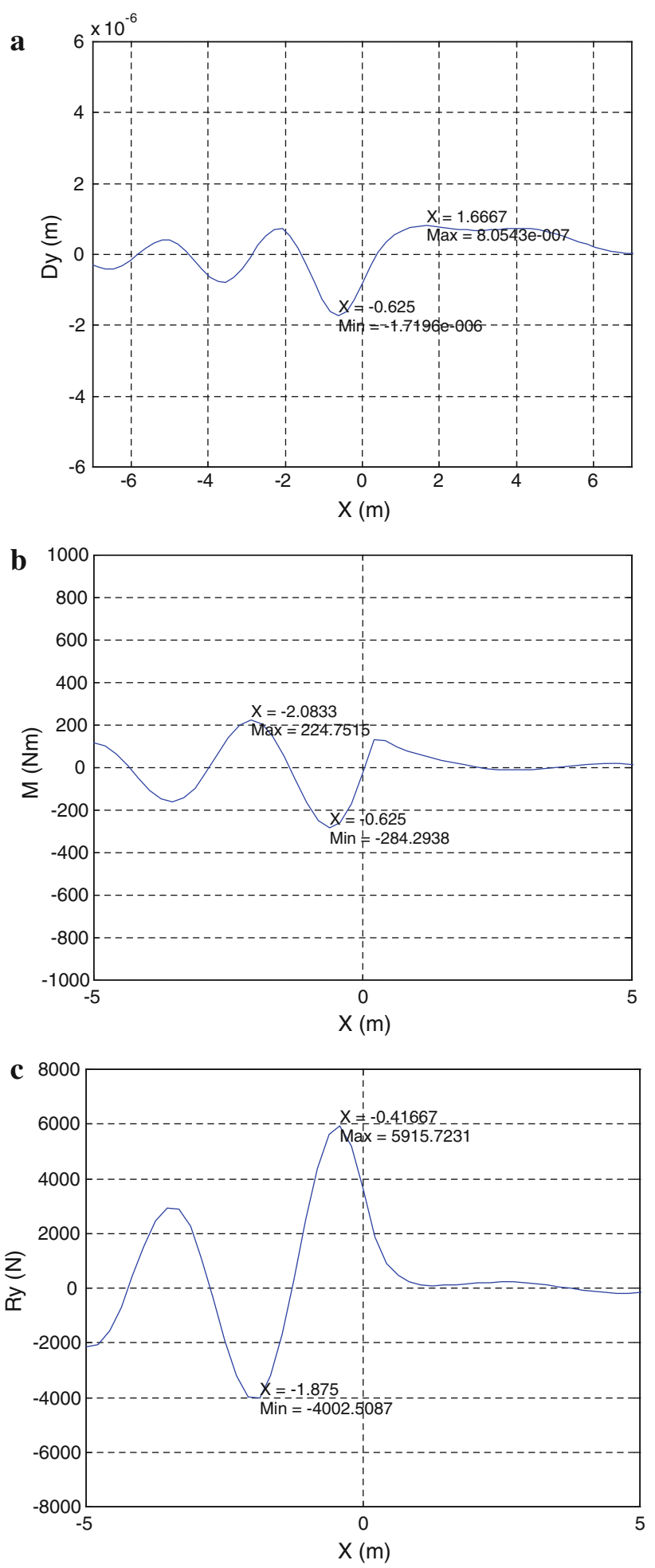

Fig. 13 An example of the bending moment deformation trend and the response. a Deformation, $\mathbf{b}$ bending moment, and $\mathbf{c}$ response

response on the bed surfaces corresponds a bending moment decrease.

We observe an equivalent behavior in the combinations Nos. 9 and 10, in which from a variation of the ballast modulus follows both an increase of the response transferred to the superstructure and a bending moment decrease in the rail.

In the remained cases there are not substantial variations either in the bending moment on the rail, or in the response applied on the bed surfaces.

\section{Conclusions}

The sensitivity analysis, on the mechanical and geometrical parameters that mainly condition the operation of the railroad superstructure at high speed, has allowed to draw some useful considerations for rational design which takes into account the dynamic effects.

In general, we have verified that at the lowest frequencies the superstructure response is not at all conditioned by the variation of the geometrical parameters and is barely conditioned by the variation of the mechanical ones.

In every other cases to an improvement of the mechanical characteristics of one of the layers (ballast, sub-ballast, super-compacted layer, soil embankment) corresponds to an increase of the load on the bed surfaces and a bending moment decrease on the rail. On the contrary to a decrease of the layers mechanical characteristics corresponds to a decrease of the load transferred to the bed surfaces and an increase of the bending moment on the rail.

Moreover, from the analysis of the interaction among all the parameters involved, we draw the following design indications:

(1) The use of the embankment soil of higher quality entails a stress decrease both on the embankment and on the rail;

(2) A nearly equal to the previous effect can be obtained with the employment of an higher sub-ballast thickness from 12.0 to $20.0 \mathrm{~cm}$; rather than with an improvement of the crushed stone employed;

(3) The structural responses of the bed surfaces and of the rail do not change in a substantial way by decreasing from 50.0 to $35.5 \mathrm{~cm}$ the ballast thickness;

(4) An increase of the super-compacted thickness, even if it does not give the same performances achievable in the cases Nos. 1 and 2, entails a better structural response compared to the increase of the ballast thickness only.

In conclusion from the critical analysis of the standard railway superstructure, adopted in Italy for the high speed, the authors draw the following design proposal which can guarantee a more effective structural response:

(1) The introduction of a sub-ballast thickness of $20.0 \mathrm{~cm}$ instead of the present $12.0 \mathrm{~cm}$; 
(2) The realization of a super-compacted layer with thickness of $45.0 \mathrm{~cm}$ instead of $30.0 \mathrm{~cm}$;

(3) The retention of the ballast thickness of $50.0 \mathrm{~cm}$ considered that, in addition to the dynamical effects, it is needed to guarantee a suitable distribution of the loads when they are transferred in a nearly static condition;

(4) The employment of a soil embankment, possibly granularly stabilized, that can guarantee a resilient modulus $M_{\mathrm{r}} \geq 120 \mathrm{MPa}$.

Open Access This article is distributed under the terms of the Creative Commons Attribution License which permits any use, distribution, and reproduction in any medium, provided the original author(s) and the source are credited.

\section{References}

1. Kenney JT (1984) Steady state vibrations of beam on elastic foundation for moving load. J Appl Mech 21:359-364

2. Fryba L (1972) Vibration of solids and structures under moving loads. Noordhoff International Publishing, Groningen

3. Gazetas G, Dobry R (1984) Simple radiation damping model for piles and footing. J Eng Mech 110:937-956. doi:10.1061/ (ASCE)0733-9399(1984)110:6(937

4. Sun L (2001) A closed-form solution of Bernoulli-Euler beam on viscoelastic foundation under harmonic line loads. J Sound Vib 242:619-627. doi:10.1006/jsvi.2000.3376

5. Mallik AK, Chandra S, Singh AB (2006) Steady-state response of an elastically supported infinite beam to a moving load. J Sound Vib 291:1148-1169. doi:10.1016/j.jsv.2005.07.031

6. Sun L, Luo F (2008) Steady-state dynamic response of a Bernoulli-Euler beam on a viscoelastic foundation subject to a platoon of moving dynamic loads. J Vib Acoust 130:19. doi:10. $1115 / 1.2948376$

7. Shot SH (1992) Eighty years of Sommerfeld's radiation condition. Hist Math 19:385-401. doi:10.1016/0315-0860(92)90004-U

8. Lysmer R, Kuhlemeyer K (1969) Finite dynamic model for infinite media. J Eng Mech 95:859-877

9. Gomes Correia A, Cunha J, Marcelino J, Caldeira L, Varandas J, Dimitrovová Z, Antão A, Gonçalves da Silva M (2007) Dynamic analysis of rail track for high speed trains. 2D approach. In: Sousa LR, Fernandes MM, Vargas Jr EA (eds) Applications of computational mechanics in geotechnical engineering V. Proceedings of the 5th international workshop, Guimaraes, 1-4 April 2007. Taylor \& Francis, London. ISBN: 978-0-415-43789-9. doi:10. 1201/9781439833414.ch39

10. Thach P-N, Kong G-Q (2012) A prediction model for traininduced. Electron J Geotech Eng, 17 Bund. X:3559-3569. ISSN:1089-3032

11. Luna R, Jadi H (2000) Determination of dynamic soil properties using geophysical methods. Proceedings of the 1st international conference on the application of geophysical and NDT methodologies to transportation facilities and infrastructure. Federal Highway Administration, St. Louis

12. Agostinacchio M, Diomedi M, Olita S (2009) The use of marginal materials in road constructions: proposal of an eco-compatible section. In: Loizos A, Partl M, Scarpas T, Al-Qadi I (eds) Advanced testing and characterisation of bituminous materials. Taylor \& Francis Group, London, vol 2, pp 1131-1142. ISBN:9780415558549. doi:10.1201/9780203092989.ch109

13. ANSYS Inc. ANSYS element reference. http://www.ansys.com

14. Ciampa D, Olita S (2007) The use of the UNIBAS-MPT triaxial press in the definition of the master curves of the complex modulus of asphalt concrete. In: Loizos A, Scarpas T, Al-Quadi I (eds) Advanced characterisation of pavement and soil engineering materials. Taylor \& Francis Group, London. vol 1, pp 195-203. ISBN:9780415448826 